Martina Pavlíková in Bojan Žalec

\title{
Boj za človekov jaz in pristnost: Kierkegaardova kri- tika javnosti, uveljavljenega reda, medijev in lažnega krščanstva ${ }^{1}$
}

\section{Struggle for the Human Self and Authenticity: Kierkegaard's Critique of the Public, Established Or- der, Media, and False Christianity}

Povzetek: Prispevek predstavlja Kierkegaardovo pojmovanje duhovno razvite osebnosti, ki jo Kierkegaard imenuje posamičnik, in dejavnikov, ki človeku preprečujejo, da bi to postal. Avtorja izpostavljata štiri take dejavnike: javnost, uveljavljeni red, novinarstvo in tisk ter lažno, nepristno krščanstvo. V tem kontekstu pojasnjujeta Kierkegaardove pojme jaza oz. sebstva, množice, resnice ter pomen notranjosti, radikalnosti in strasti. Analiza kaže, da je v samem središču Kierkegaardovega razumevanja človeka in družbe odnos »človek-Bog« v svoji kristocentrični obliki. Prav tako postane očitno, da so kljub Kierkegaardovemu poudarjanju subjektivnosti in pomena notranjosti trditve, da je Kierkegaard individualist, neutemeljene. Kierkegaard je bil odnosni mislec, ne samo v vertikalnem odnosu »človek-Bog", ampak tudi v horizontalnem, družbeno-socialnem odnosu »človek-človek«, saj je bil njegov cilj in ideal oblikovanje skupnosti. Slednjo je razlikoval od množice kot skvarjene oblike socialnosti. V pravi skupnosti so ljudje povezani po Bogu, gre za vzorec »človek-Bog-človek«. Končna ugotovitev avtorjev je, da je Kierkegaardov ideal skupnost, ki jo prežema kristocentrična radikalna poslušnost Bogu - takšna skupnost pa je v nasprotju z omenjenimi štirimi negativnimi dejavniki razvoja posamičnika. To ne preseneča, saj so temelj skupnosti v Kierkegaardovem smislu Bog in posamičniki, t.j. osebe, ki živijo iz svojega pristnega odnosa z Bogom in na tej podlagi gojijo tudi svoje odnose z drugimi.

Ključne osebe: Kierkegaard, posamičnik, sebstvo, skupnost, javnost, uveljavljeni red, mediji, lažno krščanstvo

Članek je nastal v okviru raziskovalnega programa Etično-religiozni temelji in perspektive družbe ter religiologija v kontekstu sodobne edukacije in nasilje (P6-0269) in temeljnih raziskovalnih projektov Vračanje religioznega v postmoderni misli kot izziv za teologijo (J6-7325), Oživljanje kozmične pravičnosti: poetika feminilnega (J6-8265) in Medreligijski dialog - temelj za sožitje različnosti v luči migracij in begunske krize (J6-9393). Program in projekte je finančno podprla Javna agencija za raziskovalno dejavnost Republike Slovenije (ARRS). 
Abstract. The authors present Kierkegaard's conception of spiritually developed personality that Kierkegaard calls a single individual, and the factors that prevent a person from becoming a single individual. There are four factors stressed by the authors: the public, the established order, journalism and press, and pseudo Christianity. In this context, Kierkegaard's notions of self, crowd and truth are explained, and the importance of innerness, radicalism and passion. The analysis shows that it is at the heart of Kierkegaard's understanding of man and society the relationship "human-God", in its Christocentric form. It also becomes apparent that despite Kierkegaard's stressing of subjectivity, and importance of innerness, the claims that Kierkegaard is an individualist are unjustified. Kierkegaard is a relational thinker, not only in the vertical respect, "man-God" relationship, but also in the horizontal, social one, "man-man" relationship, as his goal and ideal is the formation of a community. He distinguished the latter from the crowd as a corrupt form of sociality. In real communities, people are connected via God - the matrix is "man-God-man". The authors' final observation is that Kierkegaard's ideal is a community pervaded with Christocentric radical obedience to God. Such a community is in opposition with the aforementioned four negative factors of shaping of single individual. This is not surprising because the cornerstones of the community in Kierkegaard's sense are God and single individuals, i.e. the persons who live out of their genuine relationship with God and on this basis also cultivate their relationship with others.

Keywords: Kierkegaard, single individual, self, community, public, established order, media, pseudo Christianity

\section{Pomen posamičnika ${ }^{2}$}

Søren Kierkegaard (1813-1855) je znan po svoji filozofsko-teološki naravnanosti na človeka in človekov odnos do Boga in drugih. V svojih spisih se odziva na probleme (sodobnega) človeka in družbe: izguba vrednot (Omarova et al. 2018), subjektivnost, vpliv novinarstva oz. medijev, ${ }^{3}$ »kriza« Cerkve /.../ Na začetku svoje knjige Strah in trepet svoj čas označuje takole: »Naša doba je ne samo v poslovnem svetu, ampak tudi v svetu idej organizirala pravo razprodajo. Vse se da dobiti za tako ugodno ceno, vprašanje pa je, ali sploh obstaja kdo, ki bo dal ponudbo za nakup« (Kierkegaard 1983, 5). Posebej opozarja na dve lastnosti, ki sta pri sodobnem človeku odsotni: 1. enotnost besed in dejanj v smislu "storil je, kar je rekel, in povedal, kar je storil«; 2. globoka vera (5).

2 Izraz »posamičnik» je zdaj že ustaljen prevod za Kierkegaardov danski izraz »den Enkelte«. V grobem ga lahko opredelimo kot duhovno prebujenega posameznika, ki živi iz pristnega odnosa z Bogom (Zupet $1987,5)$. Prevod "posameznik« ni ustrezen, ker iz tega, da je nekdo posameznik, še ne izhaja, da je tudi posamičnik.

3 Lesková in Michal Valčo 2017; Marfil-Carmona in Ortiz-Cobo 2019; Tyurikov et al. 2018; Zheltukhina et al. 2017. 
Za Kierkegaarda je pomembneje biti človek kot biti uspešen, saj uspešni ljudje na tem svetu »pred Bogom nimajo nobenega jaza« $(1980,35)$. Samo tisti, ki je pred Bogom jaz oz. sebstvo - posamičnik - lahko globlje spozna vrednote, ki so po Kierkegaardu strogo subjektivne, predvsem pa religiozne. V Kierkegaardovih delih lahko razločimo tri ravni aksiološkega dojemanja (Máhrik 2017b, 128-129). Prvič, Kierkegaard pojmovanje človeka in vrednot, ki jih ta živi, zgodovinsko sidra v krščanstvu, kjer je v središču odnos »Bog-človek «. ${ }^{4}$ Druga raven je filozofska. Tu njegova teza o absolutnem paradoksu predstavlja osnovo za avtentično življenje človeka, in to ne glede na »individualne pogoje posameznikovega življenja in tipologijo njegove osebnosti«. Tretjič, notranja gonilna sila človekovega življenja mora biti ljubezen, ki presega zunanje okolje. »Kierkegaardov koncept absolutnega paradoksa tvori osnovo radikalne ljubezni, ki je pravi motiv človekovega razmišljanja in delovanja« (ibid.). Resnična ljubezen je nesebična - osredotočena je na Boga in dobro drugega, ne pa na lastni užitek, ki je v krščanstvu kot tak, sam po sebi, po mnenju Kierkegaarda ničvreden.

Kierkegaard je kritičen do svojega časa, ki ne zahteva človekovega »jaza«. Človek se ukvarja s »spodobnimi« rečmi ("poročiti se in roditi otroke, biti deležen časti in spoštovan« itd.), pri tem pa se ne zaveda, da v globljem smislu nima jaza, kar pa sveta ne skrbi (Kierkegaard 1980, 32). Uvidel je, da je največje tveganje, hazard, v tem, da bi se človek »izgubil« (ibid.). Ta izguba pomeni, da človek postane del množice ${ }^{5}$ in se posledično odtuji sam sebi - manjka mu lastnih misli in odločitev. Živi samo zato, da čim lažje doseže »lažni« uspeh, bogastvo, priznanje. Hkrati pa se boji konfrontacij, boji se za lastni ugled in se prilagaja zunanjim, družbenim vzorcem in zahtevam. Kierkegaard je zapisal: »Namesto da postanemo mi sami, postanemo številka, samo še en človek« (34) - omejen človek, ki izgubi pogum, ne zanimajo ga duhovne stvari, njegovo razmišljanje se giblje na površju (Platovnjak 2017, 339-343; Platovnjak in Svetelj 2018, 380-385). Kierkegaard pa poudarja čistost srca - poštenost v razmišljanju in delovanju:

»[č]e je človekovo srce motno, ni globoko, ampak površno. V tem smislu je Kierkegaard primer borca proti površnosti. Da, površnost zanika vse globoko in zato vse dragoceno. Z njegovim bojem proti površnosti je še danes aktualen. Kierkegaard je kot osamljeni krakajoči krokar, ki svari pred izgubo človeških vrednot.« (Králik 2007, 116)

Po drugi strani pa človek, ki izgubi sebe, ravno s tem »pridobi naraščajočo zmožnost da mu gre sijajno v poslu in družabnem in družbenem življenju, resnično, da doseže velik uspeh v svetu« (Kierkegaard 1980, 34). Kierkegaard poudarja, da

\footnotetext{
Binetti in Pavlíková. 2019; Máhrik 2018; Martin, Ortiz-Cobo in Kondrla. 2019; Valčo in Šturák. 2018; Tavilla, Kralik, Webb, Jiang in Aguilar 2019; Tavilla, Králik in Roubalová 2019.

5 Za dodatne pojasnitve Kierkegaardovega pojma »množica« gl. spodaj in Žalec 2015, 221-223, 226-228. Slabih sto let po Kierkegaardu, na predvečer kataklizme 2. svetovne vojne, je Ortega y Gasset videl v pojavu človeka množice glavno težavo sodobnosti, ki ima (lahko) katastrofalne posledice (Ortega y Gasset 1985). Po strašni izkušnji 20. stoletja bi težko rekli, da se je motil.
} 
moramo biti drzni, da moramo tvegati, kajti tisti, ki (zaradi strahopetnosti) ne tvega, si pridobi zemeljske koristi, vendar pa izgubi samega sebe (34-35).

Kierkegaard je uvodne vrstice svojih knjig pogosto začel z nagovarjanjem posamičnika. Tako je na primer zapisal:

"Spoštovani! Sprejmite to posvetilo, vam ga na slepo podarim. Prav zato, ker ga ne moti nobeno preudarjanje, je iskreno! Ne vem, kdo ste, ne vem, kje ste, niti ne poznam vašega imena. Sploh ne vem, ali obstajate ali pa ste obstajali in vas ni več; ali pa bo kdaj šele prišel vaš čas. Pa vendar ste moje upanje, moje veselje, moj ponos, čast v negotovosti.« (Kierkegaard 2010, Pap., VII. 1 A 176)

Kierkegaard meni, da je najpomembneje, da človek postane posamičnik (Martín 2017, 100-101). Razlog je v tem, da se samo posamičnik lahko osvobodi množice, začne kritično razmišljati, presojati, se izražati svobodno in brez strahu - ni namreč odvisen od odnosov, ki mu prinašajo koristi ali družbeni prestiž. Pravi in resnični odnosi temeljijo na vrednotah, ne na izračunih. Sredi pritiska družbe in množice, in prav zaradi njega, je potrebna perspektiva posamičnika. Ta perspektiva je zasidrana $v$ eksistencialnem življenju v Kierkegaardovem smislu - njegova temeljna značilnost je presežna, transcendentna razsežnost človeka, saj »človek ni Bog in zato ne more dojeti resničnosti svojega bitja z Njegove (absolutne) perspektive, ampak le z (omejenega) človeškega gledišča (Máhrik 2015, 51). Posamičnik je izviren zato, ker ni zgolj prevzemalec misli in stališč drugih, temveč oblikuje svoja. S tem postane izviren v svojem znanju, biti in ravnanju. Posamičnik ne podlega javnemu mnenju, ki ga lahko

"v retoriki razumemo kot communis oppinio, skupni nazor ali mnenje, torej kot vse predsodke, dogme, mite, razširjene $v$ družbi, v občinstvu ali kar $v$ celotni kulturi oz. človeštvu, ki se nekritično sprejemajo kot dani, iz katerih se izhaja in ki niso sporni. Retor jih pozna, jih uporablja ali pa po potrebi razbija. Običajno jim rečemo predsodki. In pogosto jih identificiramo le, če jih gledamo od zunaj, z drugega kulturnega gledišča ali časa, pri čemer se je težko izogniti tveganju, da ne zapademo drugim predsodkom, predsodkom našega lastnega časa.« (Štúr 2011, 32)

Kierkegaard je sokratsko vodil bralca k osvoboditvi od tega vpliva - $\mathrm{k}$ temu, da bi presojal sam. Značilnost posamičnika je, da ni anonimen, ni izgubljen v množici in je zmožen prevzeti odgovornost za svoje odločitve. Kiekegaarda je navdušil Sokrat in njegov lastni odnos do posamičnika, do katerega je bil vedno ponižen in hkrati ponosen (Kierkegaard 1985, 11). Za Kierkegaarda je biti posamičnik tako pomembno, da je $v$ dnevnik zapisal: "Ta kategorija posamičnika je tako močno povezana z mojim imenom, da si želim, da bi mi na nagrobnik napisali: ıTu počiva posamičnik.» (Kierkegaard 2010, Pap. VIII 1 A 108). Da postanemo posamičniki, je zelo pomembno tudi zato, ker človeka, ki ni posamičnik, ampak zgolj del množice, zlahka zavede goli govor, ki je abstrakten in neoseben oz. brezoseben. Če 
človek ne razmišlja sam in drugega ne posluša zares, sčasoma popolnoma preneha razmišljati, se zgolj prilagaja ter sledi množici (oz. njenemu vodji); ${ }^{6}$ ni odgovoren in ne razmišlja konkretno. Kierkegaard pri tem meri na duhovnike, ki so podlegli značaju tistega časa in na teologe, ki so se zgolj prilagajali filozofiji in medijem, ki so takrat začeli delovati.

\section{Družbene strukture, ki posamičnika uničujejo}

\subsection{Javnost}

Kierkegaard se v svoji knjigi Dve dobi osredotoča na fenomen javnosti in v tem kontekstu kritizira sredstva množične komunikacije:

»Le v odsotnosti močnega skupnostnega življenja, katero vključuje /.../ konkretnost, ustvari tisk /.../ abstrakten koncept, imenovan sjavnostı, ki jo sestavljajo neoprijemljivi ljudje, ki se ne bodo nikoli združili, ker se niti ne bi mogli združiti, v enotno situacijo ali organizacijo, vendar jih hkrati dojemamo kot eno enoto. Javnost je skupina -presega vse ljudi skupaj, vendar te skupine nikoli ne moremo poklicati na pregled, niti enega samega zastopnika, ker je javnost sama po sebi absolutna abstrakcija." (Kierkegaard 1978, 91)

Sodobna doba je nesposobna strasti, uniči vsako prizadevanje za svojevrstnost, javnost pa postane »subjekt«, ki vključuje vse. Človek mora postati posamičnik, zavračati množico, maso, javnost in pred Bogom biti oziroma bolje postajati jaz, sebstvo. Postajati mora božja podoba - to, kar mu je Bog namenil postati (Žalec 2014,$205 ; 211 ; 2015,222-223$ ). Le takrat je pristen, resnično on sam in se manifestira takšen, kot v resnici je. Z ločitvijo od množice človek pridobi najvišje, »to je edino, kar je vredno živeti in kar bo trajalo vso večnost!« (Kierkegaard 1993, 135). Kierkegaard je kritičen do drže človeka njegove dobe, do njegove morale, vrednot in strahov, zato poziva in spodbuja, hrabri:

Skrajni primer odsotnosti vsakega pravega mišljenja je nacistični zločinec Adolf Eichmann, kot ga je opisala Hannah Arendt v svoji knjigi Eichmann v Jeruzalemu (Arendt 2007). Jerome Kohn je njeno oceno Eichmanna z vidika, o katerem govorimo tu, strnil takole: »Eichmann je lahko računal, ni pa mogel misliti« (Kohn 2018, xxii). Totalitarni sistemi pa niso želeli doseči take odsotnosti samo pri svojih uslužbencih, ampak tudi pri žrtvah. To je bil sestavni del njihovega razčlovečenja. Arendtova se ni nikoli naveličala poudarjati, da je temeljno, za kar si moramo prizadevati, pa če smo še v tako težki situaciji, da mislimo. Dokler mislimo, nismo premagani, nismo razčlovečeni, in do takrat je upanje. To njeno prepričanje je izviralo tudi iz njene lastne izkušnje internacijskega taborišča v Franciji, ko je opazila na sebi njegove učinke: začela je postajati otopela, apatična in mehansko izpolnjevati ukaze. Ob tem se je zdrznila in si zabičala: »Misli!«. Vendar odsotnost mišljenja, o kateri tukaj govorimo, ni prisotna samo v skrajnih razmerah totalitarizma ali taborišč, ampak je značilna tudi za vse tiste pojave, ki jih označujemo z izrazom »okostenelo mišljenje» (Kohn 2018, xix-xxii, xxv), in seveda za človeka množice. Zato tak človek ni sposoben niti empatije niti dialoga. Ortega y Gasset uporablja izraz »človek-masa« in o njem pravi: „Gre /.../ za hermetičnega človeka, ki dejansko ni odprt za nobeno višjo instanco (Ortega y Gasset 1985, 232). 
"Ne bojte se sveta, ne bojte se revščine in bede in bolezni in pomanjkanja in stiske in krivičnosti ljudi, njihovih žalitev, grdega ravnanja; ne bojte se ničesar, kar lahko poškoduje samo zunanjega človeka; ne bojte se tistih, ki lahko ubijejo telo, ampak se bojte samih sebe, bojte se tistega, kar lahko ubije vero in na ta način ubije Jezusa Kristusa za vas - pohujšanja, ki ga zagotovo lahko stori nekdo drug, ki pa je vendarle nemogoče, če ga vi sami ne sprejmete. Strah in trepet zato, ker se vera nosi v krhkem glinenem vrču, $v$ možnosti pohujšanja. Blagor tistemu, ki se ne pohujša nad njim, ampak veruje.« $(1991,76)$

$\mathrm{V}$ tem duhu doživlja tudi osebne napade, ki mu jih je prinesla kritika časopisa Korzár: »Hvala Bogu, da sem bil izpostavljen napadu smeti." (Kierkegaard 2010, Pap. VII 2 B 229) Zlorabo javnosti ocenjuje kot zelo veliko zlo in nevarnost:

"Javnost pa je abstrakcija. Pri sprejemanju istega mnenja kot te ali one določene osebe človek ve, da bodo te izpostavljene enaki nevarnosti kot on sam, da bodo z njim zašle, če bo mnenje zmotno itd. Toda sprejeti enako mnenje kot javnost je varljiva tolažba, saj javnost obstaja samo in abstracto. Čeprav nobena večina še nikoli ni bila tako gotova glede tega, da ima prav in ima prednost kot javnost, je to le rahla tolažba za posameznika, saj je javnost fantom, ki ne dovoljuje nobenega osebnega pristopa. Če danes nekdo sprejme mnenje javnosti, in je jutri izžvižgan in zavržen, je tista, ki ga bo izžvižgala in zavrgla, javnost. Generacija, narod, občni zbor, skupnost, človek še vedno imajo odgovornost, da so nekaj, lahko so zasramovani zaradi nestanovitnosti in nezvestobe, javnost pa ostaja javnost. Ljudstvo, zbor in človek se lahko tako spremenijo, da lahko rečemo: niso več isti; javnost pa se lahko spremeni ravno v svoje nasprotje pa je še vedno ista - javnost.«(Kierkegaard 1978, 92)

Danes na javnost vplivajo mediji in različne tehnologije. Njihov cilj naj bi bil poenostavitev in pospešitev človekovega življenja, kar bi moralo potekati v etičnih okvirih. Vendar pa, žal, dejansko etika in moralnost ostajata v ozadju, kar odločilno prispeva k krizi celotne sodobne družbe (Králik in Tinley 2017, 25-29; Kondrla in Repar 2017, 19-24). Del krize je tudi kriza skupnosti. Samo oblikovanje javnosti še ne oblikuje skupnosti. Seveda je res, da če bere, posluša ali gleda samo ena oseba, sama ni javnost, vendar pa se moramo zavedati, da tudi če to počne veliko posameznikov, morda vsi, to še vedno ne pomeni, da tvorijo skupnost, da med njimi obstaja pripadnost. Javnost, ki ne temelji na skupnosti, pa ima zelo nevaren potencial. Ima izredno moč vplivanja na posameznika, lahko ga zelo prizadene, ne premore pa etične regulacije, ki jo zagotavlja skupnost. Kierkegaardove analize in refleksije so zato izjemno dragocene pri razvijanju zavedanja o povedanem in za iskanje rešitev za probleme, ki jih javnost prinaša. 


\subsection{Uveljavljeni red}

Kierkegaard je prišel v konflikt tudi s cerkvenimi voditelji (Mynster, Martensen, Grundtvig). Svojo kritiko je podal (tudi) s kritiko uveljavljenega reda in njegovega pobožanstvenja:

„Vendar uveljavljeni red /.../ vedno vztraja, da je objektiven, višji od vsakega posameznika in subjektivnosti. $V$ trenutku, ko se posameznik noče podrediti uveljavljenemu redu ali celo postavlja pod vprašaj njegovo resničnost, da, ko ga obtožuje, da je neresnica, medtem ko razglaša, da je on sam $v$ resnici in od resnice -takrat imamo trk. Uveljavljeni red čisto pravilno postavlja vprašanje: Kdo pa misli, da je, ta posameznik? Ali morda misli, da je Bog ali, da ima neposreden odnos z Bogom ali vsaj, da je več kot človek?» (Kierkegaard 1991, 86)

Za Kierkegaarda je bistveno pričevanje za resnico, ki »preobraža zunanjost v notranjost“ (Kierkegaard 1991, 86). Problem svojega časa vidi v tem, da uveljavljeni red usmerja Cerkev: „Uveljavljeni red je začel tudi trk med posamičnikom in uveljavljenim redom, začel z odnosom posamičnika do Boga, toda zdaj mora biti to pozabljeno, most porušen in uveljavljeni red pobožanjen.« (88)

Uveljavljeni red je odpravil iskren in pristen odnos človeka do Boga in postal merilo vrednot in vere. Kierkegaard pa nasprotno poudarja, da posamičnik kaže resnico krščanstva. Te resnice ne najdemo pri pastirjih ali profesorjih, temveč v posamičniku, ki je pričevalec resnice. Kierkegaardova kritika se osredotoča na tiste, ki poudarjajo objektivno znanje v nasprotju s pristnim odnosom človeka do Boga (Štúr in Mitterpach 2017, 38-39). Ironično pripominja: »Ah, sedaj je vse tako, kot mora biti; zdaj je uveljavljeni red pobožanjen - če bi Kristus prišel na svet, bi zdaj najprej postal profesor in bi vztrajno napredoval, vse v skladu s tem, ko bi postajalo bolj očitno, da je v resnici« $(1991,89)$. Kierkegaard prav tako kritično opozarja na spremenljivost »merila« resnice: "Če ste študent, potem ste lahko prepričani, da je profesor merilo in resnica. Če ste duhovnik, potem ste lahko prepričani, da je škof pot in življenje» (90). Kritizira dejstvo, da se resnica relativizira, prilagaja dogodkom ali osebam. Ta resnica je postala končna, dosežena brez napora, brez boja, simbol lažnega čaščenja in priznanja. Pravi znak resnice pa je, da trpi. Kierkegaard je človeka opredelil kot »bitje, ki je zunaj resnice» $(1985,13)-$ takšno je njegovo izhodišče. Človek je kot učenec, ki potrebuje svojega učitelja. Ker sokratski učitelj, ki predstavlja zgolj in povsem človeško perspektivo razmišljanja, svojemu učencu ne more zagotoviti ničesar, kar bi bilo v eksistencialnem pogledu bistveno, mora obstajati učitelj, ki je absolutno večji od človeka. Takšno gledanje odpira prostor predstavnosti, imaginariju, v katerem se nahajata človek, ki je izgubil resnico, in učitelj, ki je tako človeške kot božanske narave (Máhrik 2017a, 79). Ta lahko pomaga človeku v njegovem pristnem boju za dragoceno življenje, usmerjeno proti večnosti. Človek se rodi v neresnici, in to po svoji lastni krivdi. Ta krivda je po Kierkegaardu greh. Človek se samo zdi svoboden, „v resnici pa je nesvoboden in vezan in izključen« (Kierkegaard 1985, 15). Človek je »prost 
resnice« oz. »izključen « iz resnice, iz katere se je izključil sam. Zato ni prost, z drugimi besedami - sam se ne more osvoboditi (15). Človek se je namreč soočil z izbiro med svobodo in nesvobodo; prostovoljno si je izbral nesvobodo. $V$ nesvobodi uporablja moč svoje svobodne odločitve, kar pa omogoča samo, da postane po svoji lastni krivdi suženj lastnih strasti in nagonov. Rezultat je njegovo trpljenje, tesnoba in bolezen za smrt (Tavilla 2017a, 163-173). Za osvoboditev mora slediti učitelju, ki je absolutno večji od človeka.

Kierkegaard se od sveta distancira: "S svetom nimam prav ničesar opraviti« (Kierkegaard 1990, 91). Človeka poziva, naj ravna podobno; pomembno je upoštevati, da za Kierkegaarda biti posamičnik pomeni "[i]meti in hoteti imeti vest" (ibid.). Vest se nato poveže z resnico, govorjenjem in življenjem resnice. Ljudje z vestjo, posamičniki, so odločilnega pomena $v$ svetu, $v$ katerem resnico ne le prekrivajo in z njo varajo, ampak ljudi obravnavajo dobesedno kot norce, ki jim je mogoče natveziti vse, če se jim le laska (ibid.). Tu meri Kierkegaard predvsem na politike in različne ideologe, ki so tako prišli do moči in zavladali množicam.

\subsection{Novinarstvo}

Kierkegaard kritizira novinarje, ki so s pomočjo tiska »demoralizirali državo« in prinesli škodo: „Kar želi doseči tisk, je publiciteta, publiciteta pa je moč laži, /.../ moč pesti! To spominja na Goethejeve besede: odstranili so hudiče in dobili demone« (Kierkegaard 2010, Pap. IX A 468).

Hkrati se že v 19. stoletju zaveda neizmerne moči novinarstva: "Z novinarjem se ni mogoče prepirati. Skriva se, ne more biti ujet in proti človeku naščuva tisoč ljudi, s katerimi ta nima nič skupnega. Ti so potem predmet posmeha in pomilovanja. So krivi in hkrati nedolžni« (Pap. IX A 200). O novinarjih pravi: »Vi ste najhujši ljudje, novinarji! Od vseh tiranov ste najbolj ogabni, tiranizirate $s$ strahom pred ljudmi!« ( Pap. X, 3 A 275). Zanimiva je njegova trditev, da je »tisk povzročil najgloblji padec človeštva, ker omogoča upor od spodaj. To je odlično orožje, zasnovano tako, da ubije vse, kar nekaj pomeni, zato so lahko gotovi samo tisti, ki ne pomenijo nič. Teh je največ in tako je 'množica' (zlo načelo) postavljena kot vrhovni vladar" ( Pap. XI, I A 242). "Modrost" svojega nasprotnika Mynsterja primerja $z$ »novinarsko ravnijo, politiko (Pap. X, 4 A 348). Bil je kritičen do škofa Martensena, ki je tisk uporabil "za zavajanje, kar bi lahko imenovali novinarska nespodobnost ... " (Pap. XI, 3B 49), in opozarjal na manipulacijo z martensensko množico. Tudi sam je bil predmet posmeha in kritike tiska in novinarjev (Hajko 2011) - in se je vsekakor dobro, že kar vizionarsko oz. "preroško", zavedal nevarnosti, ki jo mediji predstavljajo. Še bolj to velja danes, ko imajo nedvomno neprimerno večji vpliv in pomen kot v obdobju Kierkegaarda (Lesková in Valčo 2017, 325). Ta vpliv je pogosto negativen - na primer uničevanje občutljivosti za nasilje in smrt (drugih):

»Mediji posredujejo prekomerno izpostavljeno nasilje in smrt v svoji surovi goloti in brutalnosti. Priča smo upadanju občutljivosti za smrt s televizijskih zaslonov, strani tiska, platen kinematografov ali iz virtualne resnič- 
nosti, na primer v različnih video ali računalniških igricah. Tako človek postane imun na hipertrofiranje in tematiziranje smrti v vsakdanji resničnosti, s katero se sooča, predvsem ali najpogosteje, preko novic. " (Gabašová 2014, 28)

\subsection{Lažno krščanstvo}

Kierkegaard je kritičen do interpretacije krščanstva, ki zanika ali ignorira junaštvo, pogum vitezov vere, mučencev - tistih, ki so se zmogli žrtvovati za krščanske ideale. Zavrača krščanstvo brez žrtve in poguma (Králik 2017, 39). Ne sprejema nepristnega krščanstva, ki se izogiba nevarnosti, spopadu in vsemu, "proti čemur sta meso in kri« (Kierkegaard 1990, 101), ter radikalizira kritiko nepristnega krščanstva (svojega časa). Danska je bila takrat v gospodarski krizi in je poskušala najti način lastne "oživitve«, Kierkegaard pa - kritičen do duhovnikov, odgovornih za državo - pravi:

"Toda sekularna miselnost v nas nam ne pusti, da bi zares bili zadovoljni s tem; nikoli ni zadovoljna vse dotlej, dokler ji ne uspe uveljaviti zmote, brezbožnosti, kot člen vere, kot dolžnost, kot dogmo, kot resnično krščanstvo - tako da se lahko potem odrečemo pravemu krščanstvu kot brezbožnosti.» (102)

Meni, da imamo le dve možnosti, postavljeni smo pred alternativo »ali-ali«: ali hočemo samo eno, smo drzni, ali pa naše razmišljanje ni nedvoumno, ampak je le verjetnost. Zato je treba verjetnost zavrniti, saj je povezana s prevejanostjo, špekulacijami, izgovori, nezvestobo, tatvino in celo umorom. Zato Kierkegaard zahteva radikalnost (Tavilla, Králik in García 2018, 354) in nedvoumnost, ki se kaže $\checkmark$ pogumu. $V$ tem pogledu se njegovo stališče ujema s stališči Paula Tillicha (Králik 2015, 183-185) in Dietricha Bonhoefferja (Valčo 2017, 47-58), ki sta kritizirala družbene razmere v Nemčiji svojega časa, pa tudi, presenetljivo, Mahniča in Ušeničnika, glavnih predstavnikov katoliškega radikalizma na Slovenskem. ${ }^{7}$

\section{Zaključek}

Kierkegaard poudarja pomen subjektivnosti in pristnosti človekovega bivanja ter odločnost, ki izhaja iz globokega razumevanja smisla in usmeritve lastnega življenja. Pri tem uporablja psevdonime, ironijo in humor, ki poleg globoke filozofske refleksije in včasih strogo logično organiziranega razmišljanja tvorijo raznoliko literarno in žanrsko paleto, ki mu omogoča, da svoje uvide in dognanja izrazi na bolj plastičen in berljiv način, kot so to počeli njegovi sodobniki. Vse to je zlito $v$ njegovem slogu pisanja in razmišljanja, ki je izjemen in edinstven. Avtentičnost, pristnost po Kierkegaardovem razumevanju ni le način samoizražanja, ampak zlasti

Za podrobnejši prikaz in pojasnitev radikalnosti stališč obeh omenjenih mislecev, še posebej za predstavitev Ušeničnikovega, in mnogo nadaljnjih referenc v tem pogledu gl. Pirc 1986, tudi Pirc 2002. 
notranja resonanca in notranja privolitev posameznika v resnico. Absolutni paradoks zgodovinske inkarnacije Boga, ki uteleša odnos Bog-človek, in smrt »večnega« v svetu »časnosti« je izhodišče Kierkegaardovega eksistencialnega razmišljanja, za katerega sta pomembni radikalnost in strast. Človekov značaj lahko spoznamo po tem, $v$ kaj verjame ter za kaj je pripravljen trpeti in celo umreti. Kierkegaard je živel tisto, $v$ kar je veroval, in veroval $v$ to, kar je živel. Tako že njegova lastna osebna zgodba predstavlja močan primer boja za pristnost, radikalnost in eksistencialno strast. Vse življenje je bil pripravljen kritizirati in (zato) trpeti. Isto je zahteval od svojega "bralca« - zavzetost, izbiro in žrtvovanje, saj se mora človek za svoje ideale žrtvovati, da bi tako izbojeval svoj eksistencialni boj za notranjo celovitost in odnos z večnostjo. ${ }^{8}$ Dokaj razširjena trditev, da gre pri Kierkegaardovem konceptu pristnega individualnega življenja za eksistencialistični individualizem, ni veljavna. Čeprav Kierkegaard zelo natančno analizira človekov notranji svet, njegova izhodišča za razumevanje sveta, motive njegovega delovanja in etični okvir njegovega dojemanja, $v$ svojih analizah ne ostaja v zaprtem svetu posameznika, ampak vključuje človekov širši družbeno-socialni kontekst - prijatelje, družino, družabno življenje, akademijo, cerkev, medije itd. Poleg tega je Kierkegaard menil, da sta za to, da človek pred Bogom postane pravi jaz oz. sebstvo, potrebna dva koraka: prvi korak je izstop iz kolektiva, da se lahko človek očisti škodljivega pritiska in učinkov množice. $Z$ izpraznjenjem svojega "sebstva«, kot ga določa množica, je človek kenotično zmožen pred Bogom postati posamičnik, jaz, sebstvo. Vendar to ni zadnji cilj - končni korak je vstop nazaj v kolektiv, kjer pa mora človek graditi obliko kolektiva, ki jo Kierkegaard včasih imenuje skupnost, da bi jo razlikoval od množice. Razlikovalna značilnost skupnosti je njen tretji element, Bog kot posrednik. Takšna skupnost je odnos »človek-Bog-človek«. Prisotnost tretjega elementa, Boga, onemogoča možnost človekove nerazlikovanosti, odsotnosti jaza, saj preprečuje škodljive posledice izključno človeško posredovanega oblikovanja sebstva. Samo tako je po Kierkegaardu mogoča prava skupnost (Howles 2017, 767). Kierkegaardov končni cilj in ideal ni kak samoten posameznik, ki živi ločeno od drugih, četudi v še tako pristnem stiku z Bogom, ampak človek v skupnosti, t.j. kolektivu ljudi, ki so med seboj povezani preko (svojega odnosa do) Boga. ${ }^{9}$ Kolektiv, ki ni množica, je možno doseči, vendar samo na temelju Boga in z njegovo pomočjo. Brez Boga človek niti ne more vedeti, kdo v resnici je, saj to ve za vsakega posameznika le Bog - in le Bog nas lahko prav vodi. Nasprotno pa se človek brez Boga, ker ne ve, kdo je, da bi izvedel, kdo je, ozira po drugih in jih posnema. Vendar tudi drugi brez Boga ne vedo niti tega, kdo so sami, kaj šele, da bi vedeli, kdo so drugi (Kierkegaard 1997, 40). Zato je v družbi brez Boga tako, da slepci vodijo slepce (Bellinger 2001, 76); taka skupina pa se kaj hitro zvrne v jamo. Iz po-

8 Pri tem pa moramo opozoriti, da je Kierkegaardovo razumevanje žrtvovanja zelo kompleksno in ga ne moremo zvesti na kak preprost aktivizem. Kierkegaard izhaja iz odnosa »človek-Bog». Pravo oz. pravilno žrtvovanje je tisto, ki temelji na ljubezni do Boga in je v skladu z božjo voljo. Vsako drugo »žrtvovanje» Kierkegaard zavrača, vključno z izsiljenim »mučeništvom« (Žalec 2016; 2018). Za dodatno poglobitev razumevanja žrtvovanja v krščanstvu gl. Platovnjak 2016.

9 Slovenski filozof France Veber je tako obliko socialnosti imenoval Cerkev oz. cerkveno občestvo (Veber 2000, 134; Žalec 2002, 66). 
vedanega je torej razvidno, da so oznake Kierkegaardove »etike« kot individualistične ali celo solipsistične napačne.

Kierkegaard je prepričan, da ni tako zelo pomembno, zakaj je kdo začel kaj pomembnega, ampak to, da to počne z zavzetostjo in strastjo. ${ }^{10}$ Zaradi strasti se odloči boriti proti napačnim verskim praksam, škodljivim tradicijam, lažnim avtoritetam in neetičnim medijskim praksam (v svojem okolju). Strast je postala pomemben most, ki povezuje posameznikov notranji svet ter področji družbe in narave. Ne gre za strast v smislu svojevoljnosti ali poljubnosti, ki temelji na spontanosti, ampak za premišljen način izpolnjevanja človekovega mandata, ki vključuje odgovornost do družbe (in zanjo), katere član oz. del je. Pri tem cilj oz. ideal ni kakšno antropocentrično razkazovanje človeških sposobnosti, pač pa kristocentrična radikalna poslušnost človeka Bogu. Kierkegaardova »deontološka« etika tako predstavlja pomemben izziv, dramilo in spodbudo za našo »hedonistično« oziroma utilitaristično ustrojeno sodobno družbo.

\section{Reference}

Arendt, Hannah. 2007. Eichmann v Jeruzalemu. Ljubljana: Študentska založba.

- - - 2018. Thinking without a banister: essays in understanding, 1953-1975. New York: Schocken Books.

Bellinger, Charles K. 2001. The Genealogy of Violence: Reflections on Creation, Freedom, and Evil. Oxford: Oxford University Press.

Binetti, Maria, in Martina Pavlíková. 2019. Kierkegaard on the reconciliation of conscience. XLinguae 12, št. 3:192-200.

Gabašova, Katarína. 2014. Kierkegaard a obraz smrti vo svetle súčasnosti. Ljubljana: KUD Apokalipsa.

Hajko, Dalimir. 2011. Vrúcnost' a čin alebo Kierkegaardovské meditácie. Bratislava: Hajko \& Hajkova.

Howles, Timothy. 2017. The Undiferentiated Crowd: An Analysis of the Kierkegaardian "Single Individual« in Light of Girardian Mimetic Theory. Heythorp Journal 58, št. 5:762-770.

Kierkegaard, Søren. 1978. Two Ages. Princeton: Princeton University Press.

-- - 1983. Fear and Trembling; Repetition. Princeton: Princeton University Press.

- - . 1980. The Sickness unto Death: A Christian Psychological Exposition for Upbuilding and Awakening. Princeton: Princeton University Press.

-- -. 1985. Philosophical Fragments. Princeton: Princeton University Press.
- - 1990. For Self-examination: Judge for Yourself. Princeton: Princeton University Press.

- - - 1991. Practice in Christianity. Princeton: Princeton University Press.

- - - 1997. Christian Discourses: The Crisis and a Crisis in the Light of Actress. Princeton: Princeton University Press.

- - . 2010. Z deníků a Papírů. Brno: Centrum pro studium demokracie a kultury (CDK).

Kohn, Jerome. 2018. Introduction. V: Arendt 2018, ix-xxix.

Kondrla, Peter, in Primož Repar. 2017. Ontological consequences of the ethics of technology. Communications - Scientific Letters of the University of Žilina 19, št. 1:19-24.

Králik, Roman. 2007. Kierkegaardovo cisté srdce. V: Cistota srdca, 115-124. Ur. Cyril Diatka in Roman Králik. Nitra: UKF Nitra.

- - - 2015. Kierkegaard and his influence on Tillich's philosophy of religion. European Journal of Science and Theology 11, št. 3:183-189.

- - - 2017. Kierkegaard's interpretation of faith. XLinguae 10, št. 3:37-44.

Králik, Roman, in Susanne Jakobsen Tinley. 2017. Kierkegaard's ethics as an answer to human alienation in technocratic society. Communications - Scientific Letters of the University of Žilina 19, št. 1:5-29.

Lesková, Andrea, in Michal Valčo. 2017. Identity of adolescents and its dimensions in the relation to Mass media: Philosophical-ethical reflec-

10 O vidikih zavzetosti v okviru dialoga v javnem življenju glej Strahovnik 2017. 
tions. XLinguae 10, št. 3:324-332.

Máhrik, Tibor. 2015. Kierkegaard's Existential Ellipse of Truth. European Journal of Science and Theology 11, št. 4:43-51.

- - - 2017a. Kierkegaard's Metaethical Fragments. Ljubljana: KUD Apokalipsa in CERI-SK.

- - - 2017b. Kierkegaardian Pointers to Metaethics. European Journal of Science and Theology 13, št. 5:119-130.

- - - 2018. Truth as the key metaethical category in Kierkegaard. XLinguae 11, št. 1:40-48.

Martín, José García. 2017. The category of the single individual in Kierkegaard. European Journal of Science and Theology 13, št. 3:99108.

Martín, José García, Monica Ortiz-Cobo in Peter Kondrla. 2019. Ethics, motivation and education from the perspective of Søren Kierkegaard's philosophy. XLinguae 12, št. 4:183-191.

Marfil-Carmona, Rafael, and Monica Ortiz-Cobo. 2019. Social and philosophical representation of the immigrant in the media. XLinguae 12, št. 1:192-206.

Omarova, Leila B., Aydar M. Kalimullin, Ludmila Yu. Grudtsina, Andrey V. Korzhuev in Maria Ye. Zhukova. 2018. Philosophical anthropology in postmodernism. XLinguae 11, št. 3:76-85.

Ortega y Gasset, José. 1985. Upor množic. Ljubljana: Slovenska matica.

Pirc, Jožko. 1986. Aleš Ušeničnik in znamenja časov. Ljubljana: Družina.

- - . 2004. Ušeničnikov kulturni princip in kulturni boj v Sloveniji. V: Aleš Ušeničnik, čas in ideje: 1868-1952, 51-60. Ur. Matija Ogrin in Janez Juhant. Celje: Mohorjeva družba.

Platovnjak, Ivan. 2016. Žrtvovanje v krščanski duhovnosti. Bogoslovni vestnik 76, št. 2:245-264.

- - - 2017. Vpliv religije in kulture na duhovnost in obratno. Bogoslovni vestnik 77, št. 2:337-344

Platovnjak, Ivan, in Tone Svetelj. 2018. Anatheism - an Incentive to Discover the Importance of Discipleship in Christianity. Bogoslovni vestnik 78, št. 2:375-386.

Strahovnik, Vojko. 2017. Religija, javni prostor in zavzetost v dialogu. Bogoslovni vestnik 77, št. 2:269-278.

Štúr, Martin. 2011. Responsibility and Sensus Communis at Unamuno's, Ortega y Gasset's and Heidegger's Work. Xlinguae 4, št. 4:30-39.

Štúr, Martin, in Klement Mitterpach. 2017. Different and identical features of the philosophical, scientific, artistic and religious knowledge. European Journal of Science and Theology 13, št. 1:35-46.
Tavilla, Igor. 2017. Despair as eternal damnation of the self: A Biblical anthropology in outline. European Journal of Science and Theology 13, št. 3:163-173.

Tavilla, Igor, Roman Kralik, Carson Webb, Xiamgdong Jiang and Juan Manuel Aguilar. 2019. The rise of fascism and the reformation of Hegel's dialectic into Italian neo- idealist philosophy. XLinguae 12, št. 1:139-150.

Tavilla, Igor, Roman Králik in José García Martín. 2018. La testimonianza di Kierkegaard nel quinto centenario della Riforma. XLinguae 11, št. 1:354-361.

Tavilla, Igor, Roman Králik in Marie Roubalová. 2019. Abraham and the tortoise: eleatic variations on Fear and Trembling. XLinguae 12, št. 4:219-228.

Tyurikov, Aleksandr G., Nikolay N. Kosarenko, Tatiana B. Gvozdeva, Marianna V. Voronina, Elena Ye. Grishnova and Natalya A. Solovyeva. 2018. New social reality in the context of information and communication technologies. XLinguae 11, št. 3:37-75.

Valčo, Michal. 2017. The value of Dietrich Bonhoeffer's theological-ethical reading of Søren Kierkegaard. European Journal of Science and Theology 13, št.1:47-58.

Valčo, Michal, in Peter Šturák. 2018. The »Relational Self«: Philosophical-Religious Reflections in Anthropology and Personalism. XLinguae 11, št. 1:289-299.

Veber, France. 2000. Filozofija: načelni nauk o človeku in njegovem mestu v stvarstvu. Ljubljana: Študentska založba.

Zheltukhina, Marina R., Natalia I. Klushina, Elena B. Ponomarenko, Natalia N. Vasilkova and Anna I. Dzyubenko. 2017. Modern media influence: mass culture - mass consciousness - mass communication. XLinguae 10, št. 4:96-105.

Zupet, Janez. 1987. Uvodno pojasnilo. V: Søren Kierkegaard. Bolezen za smrt: Krščanska psihološka razprava za spodbudo in prebujo in Trije spodbudni govori, 5-6. Celje: Mohorjeva družba.

Žalec, Bojan. 2002. Spisi o Vebru. Ljubljana: Študentska založba.

- - - 2014. Ljubezen kot enost mnogoterega: kierkegaardovski pogled. Bogoslovni vestnik 74, št. 2:201-213.

- - - 2015. Človekovo nesprejemanje temeljne resnice o sebi kot izvor njegovih psihopatologij, nasilja in nesočutnosti. Bogoslovni vestnik 75, št. 2:221-231.

- - . 2016. Kierkegaard, ljubezen kot dolžnost in žrtvovanje. Bogoslovni vestnik 76, št. 2:277- 292.

- - - 2018. Kierkegaard and the ethics of sacrifice as part of the ethics of love. European journal of science and theology 14, št. 3:1-11. 